\title{
PROCEDIMIENTOS PARALELOS EN ESPAÑA Y EN EL EXTRANJERO: EL TÍTULO IV DE LA LEY 29/2015 (ARTS. 37 A 40)
}

\author{
Miguel GaRdeñes Santiago \\ Profesor Titular de Derecho internacional privado \\ Universidad Autónoma de Barcelona
}

SUMARIO: 1. PLANTEAMIENTO--2. REGULACIÓN DE LA LITISPENDENCIA INTERNACIONAL.-3. REGULACIÓN DE LA CONEXIDAD INTERNACIONAL.-4. DETERMINACIÓN DEL MOMENTO DE INICIO DE LOS RESPECTIVOS PROCEDIMIENTOS.-5. TRAMITACIÓN PROCESAL DE LAS EXCEPCIONES DE LITISPENDENCIA Y CONEXIDAD INTERNACIONALES.-6. RÉGIMEN APLICABLE A LOS PROCEDIMIENTOS INICIADOS CON ANTERIORIDAD A LA NUEVA LEY.

\section{PLANTEAmiENTO}

Como es bien sabido, la finalidad de la excepción de litispendencia es evitar que lleguen a dictarse resoluciones judiciales contradictorias. Hasta ahora, el Derecho español de fuente autónoma solo regulaba de modo expreso la litispendencia interna, entre jueces españoles, pero no la situación de litispendencia internacional o procedimientos paralelos en España y en el extranjero. Tradicionalmente, la jurisprudencia entendía que esta falta de regulación expresa debía interpretarse en el sentido de que, a no ser que hubiera un convenio internacional (o norma de la UE) que expresamente previera la existencia de un procedimiento paralelo en el extranjero (o incluso aunque ya hubiera una sentencia en el extranjero, si no se había solicitado su exequátur), dicho procedimiento no podía tenerse en cuenta ${ }^{1} \mathrm{y}$, por tanto, ello

\footnotetext{
1 En la doctrina, un ejemplo muy claro en favor de esta postura tradicional se halla en la obra de Málaga Diéguez, F., La litispendencia, Barcelona, Bosch, 1999, pp. 339-407.
} 
no impedía que pudiera iniciarse un nuevo procedimiento en España. Como puede fácilmente deducirse, este estado de cosas era fuente de inseguridad jurídica, de abusos y de comportamientos oportunistas, porque se favorecía que se presentaran demandas en España con el único propósito de bloquear el futuro reconocimiento de la resolución que llegara a dictarse en el extranjero, aun cuando el procedimiento foráneo se hubiera iniciado antes ${ }^{2}$.

La nueva Ley 29/2015, de 30 de julio $^{3}$, de Cooperación Jurídica Internacional en Materia Civil (en adelante, LCJIMC), acaba definitivamente con esta situación al regular por vez primera de manera expresa la litispendencia internacional en el Derecho interno español. La nueva regulación se contiene en el Título IV (arts. 37 a 40) de la Ley $^{4}$, y, salvo alguna diferencia, se inspira muy claramente en los arts. 33 y 34 del Reglamento de la UE 1215/2012, de 12 de diciembre (Bruselas I bis), preceptos que regulan la situación de los procedimientos paralelos en un Estado de la UE y en un Estado tercero ${ }^{5}$.

En principio, al estar incluidos en una ley de alcance general, podría pensarse que los arts. 37 a 40 de la nueva LCJIMC tendrían una vocación de aplicación amplia, aunque esta conclusión quedaría bastante matizada por el carácter subsidiario que se atribuye a la nueva ley, resultando por tanto de aplicación preferente, no únicamente lo dispuesto en las normas de la Unión Europea y en los convenios internacionales, sino también las normas especiales de Derecho interno (art. 2). En lo que atañe a la regulación de los procedimientos paralelos, ello significa que las disposiciones contenidas en los cada vez más numerosos instrumentos de la UE en materia de DIPr pre-

\footnotetext{
2 Debe tenerse en cuenta que, en el marco del hoy derogado art. 954 de la LEC de 1881, tradicionalmente la jurisprudencia exigía, como condición para el reconocimiento de la resolución extranjera vinculada al orden público procesal, que no hubiera un proceso abierto en España que pudiera desembocar en una resolución incompatible con la resolución extranjera cuyo reconocimiento se pretendiera (a este respecto, aun cuando criticara los resultados insatisfactorios de esta solución, REMIRo BRoTONS, A., Ejecución de sentencias extranjeras en España. La jurisprudencia del Tribunal Supremo, Madrid, Tecnos, 1974, pp. 253-265). En cambio, la nueva Ley 29/2015 establece en su art. 46.1.f), que constituye un motivo de denegación del reconocimiento, la existencia de un litigio pendiente en España entre las mismas partes y con el mismo objeto, pero solo en la medida en que el litigio en España fuera «iniciado con anterioridad al proceso en el extranjero», siguiendo así la tendencia de algunas resoluciones judiciales que en los últimos años también se habrían pronunciado en este sentido fundamentalmente con ocasión del reconocimiento de sentencias arbitrales extranjeras (sobre esta causa de denegación, GASCÓN INCHAUSTI, F., «Reconocimiento y ejecución de resoluciones judiciales extranjeras en la Ley de cooperación jurídica internacional en materia civil», $C D T$, vol. 7, 2015, núm. 2, p. 183). Es evidente que esta precisión del legislador debe ser saludada sin reservas, porque permite atajar las conductas oportunistas y constituye, por tanto, el complemento adecuado, en sede de reconocimiento, de la nueva regulación que la misma ley introduce en materia de litispendencia y conexidad.

3 BOE del 31.

4 Sobre estas nuevas disposiciones, Esplugues Mota, C., Iglesias Buhigues, J. L. y Palao MoreNO, G., Derecho internacional privado, Valencia, Tirant lo Blanch, 9. ${ }^{a}$ ed., pp. 170-172.

5 Como es bien sabido, la introducción de nuevas normas sobre litispendencia y conexidad «extracomunitarias» es una de las principales novedades del Reglamento 1215/2012; sobre estas nuevas disposiciones, entre otros, ZHANG, H., "Reform to the Regime of Lis Pendens in Regulation Brussels I bis and Harmonization with Chinese Jurisdiction», en Bergé, J.-S., France, S. y Gardeñes Santiago, M., Boundaries of European Private International Law, Bruselas, Bruylant, 2015, pp. 266-272; SudERow, J., «Nuevas normas de litispendencia y conexidad para Europa: ¿El ocaso del torpedo italiano? ¿Flexibilidad versus previsibilidad?», $C D T$, vol. 5 (marzo de 2013), núm. 1, pp. 195-196.
} 
valecerán sobre lo dispuesto en la LCJIMC, así como también resultarán de aplicación preferente las disposiciones de los convenios internacionales aplicables en España. En consecuencia, los arts. 37 a 40 de la LCJIMC tendrán ocasión de aplicarse sobre todo cuando el procedimiento extranjero paralelo se haya iniciado en un Estado tercero, en la medida en que no resulte aplicable un convenio que prevea la litispendencia internacional con el Estado en cuestión, o también cuando el procedimiento paralelo se haya planteado en otro Estado miembro de la UE, en los casos - cada vez menos frecuentesen que ningún instrumento de la UE resulte aplicable.

Igual que hace el Reglamento 1215/2012, la LCJIMC distingue entre «litispendencia» (cuando entre los dos procesos hay identidad de partes, objeto y causa) y "conexidad» (cuando no exista tal identidad aunque a pesar de ello las demandas estén estrechamente vinculadas) ${ }^{6}$. La idea esencial de la nueva regulación, tanto en situaciones de auténtica litispendencia como de simple conexidad, es que, siempre que el procedimiento en el extranjero haya empezado antes, podrá ser tenido en cuenta por el juez español. Por tanto, igual que ocurre con los arts. 33 y 34 del Reglamento 1215/2012, prevalece el principio prior tempore tan propio de la concepción continental de la litispendencia, frente a la aproximación anglosajona del forum non conveniens, en la que el elemento temporal es uno más a tener en cuenta, entre otros posibles ${ }^{7}$.

\section{REGULACIÓN DE LA LITISPENDENCIA INTERNACIONAL}

La litispendencia se recoge en el art. 39 que establece que, cuando en el momento de presentarse una demanda en España, exista un procedimiento anteriormente iniciado en otro Estado sobre los mismos hechos (es decir, con identidad de partes, objeto y causa) en tal caso el juez español "podrá» suspender el procedimiento, a instancia de parte y previo informe del Ministerio Fiscal, si se dan una serie de condiciones, y la principal de ellas es que el juez prevea que la resolución que llegue a dictarse en el extranjero pueda ser reconocida en España (art. 39.1). A decir verdad, esta condición, que recoge de modo expreso el art. 39.1.b), constituye el criterio fundamental para decidir sobre la conveniencia o no de la suspensión, puesto que es evidente que, si el juez español llegara a la conclusión de que la sentencia que llegara a dictarse en el extranjero no podría ser reconocida, por la razón que fuera, no tendría ningún sentido suspender el curso del procedimiento en España; es más, ello sería contrario al derecho a la tutela judicial sin dilaciones indebidas. Por ello, la condición recogida en la letra $a$ ) del mismo apartado - que la competencia del juez extranjero obedezca a una conexión razonable con el litigiono es más que una manifestación específica del criterio general establecido

\footnotetext{
6 En un claro mimetismo del Reglamento 1215/2012, el art. 40.1 LCJIMC define las demandas conexas como aquellas «vinculadas entre sí por una relación tan estrecha que sería oportuno tramitarlas y juzgarlas al mismo tiempo a fin de evitar resoluciones inconciliables».

7 Al respecto, Niboyet-Hoegy, M.-L., «Les conflits de procédures», Travaux com. fr. dr. int. pr., 1995-1998, pp. 71-86.
} 
en la letra $b$ ), por cuanto la falta de competencia del juez de origen constituye un motivo para denegar el reconocimiento de la resolución extranjera en España [art. 46.1.c) LCJIMC] $^{8}$.

Por su parte, la letra $c$ ) del art. 39.1 añade que, para decidir si suspende o no el procedimiento, el juez español deberá considerar que ello es necesario «en aras de la buena administración de justicia». Para la concreción de este concepto indeterminado, el Preámbulo de la Ley 29/2015, en su apartado VII, remite al considerando núm. 24 del Reglamento 1215/2012, que señala que deberá hacerse una apreciación de conjunto de las circunstancias del caso, y en particular de las conexiones que el asunto y las partes tengan con el Estado extranjero, de la fase en que se halle el procedimiento en el extranjero (lógicamente, cuanto más avanzado esté más motivos habrá para proceder a la suspensión del segundo procedimiento en España), y de si cabe esperar que llegue a dictarse la resolución extranjera en un tiempo razonable. Se ha señalado, a propósito de la regulación paralela contenida en el Reglamento 1215/2012, que el criterio de apreciación basado en razones de buena administración de justicia se asemejaría al test del forum non conveniens, que se basaría también en una apreciación de conjunto de las circunstancias concurrentes ${ }^{9}$. Ciertamente, esta aproximación flexible fundamentada en consideraciones de buena administración de justicia presenta concomitancias con la doctrina del forum non conveniens, pero también importantes diferencias, puesto que en la regulación del art. 33 del Reglamento 1215/2012 (y también en la del art. 39.1 LCJIMC) el criterio cronológico sigue siendo esencial.

La suspensión acordada podrá levantarse en cualquier momento, también a instancia de parte y previo informe del Ministerio Fiscal, y en consecuencia se reanudará el procedimiento, si se da cualquiera de las circunstancias que enumera el art. 39.2 de la LCJIMC, como, por ejemplo, que la jurisdicción extranjera se hubiera declarado incompetente, que el procedimiento en el extranjero se hubiera suspendido o sobreseído, que se estimara poco probable que concluyera en un tiempo razonable, que se considerara necesaria la continuación del procedimiento en España por razones de buena administración de justicia y, sobre todo, cuando se previera que la sentencia que llegara a dictarse en el extranjero no podría reconocerse en España. Bastará con que concurra cualquiera de las situaciones anteriores para que los jueces españoles puedan decidir el levantamiento de la suspensión inicialmente acordada. Si, por ejemplo, en el procedimiento extranjero se ha producido una vulneración del derecho a la tutela judicial que impida el reconocimiento de la futura resolución en España, o bien a pesar de no haberse producido vulneraciones de esta naturaleza, el curso del procedimiento en el extranjero se dilata demasiado, en tal caso podría solicitarse al juez español la reanudación del proceso. Como acertadamente se ha puesto de relieve, a propósito de la

\footnotetext{
8 Por este motivo, se ha señalado con razón que, en puridad, lo dispuesto en la citada letra $a$ ) sería superfluo (DE Miguel Asensio, P. A., «Comentario a la Ley 29/2015 de cooperación jurídica internacional en materia civil», apdo. III, en http://pedrodemiguelasensio.blogspot.com.es/).

9 Suderow, J., loc. cit., p. 195.
} 
regulación paralela contenida en el Reglamento Bruselas I bis, esta previsión sería particularmente útil para hacer frente a eventuales acciones «torpedo» que pudieran interponerse ante una jurisdicción de un país tercero ${ }^{10}$.

En definitiva, cuando regula los posibles efectos en España de un procedimiento pendiente en el extranjero, el art. 39 de la LCJIMC, en sus apartados 1 y 2, otorga al juez un auténtico poder discrecional, por el que podrá valorar si, en interés de una buena administración de justicia, es conveniente o no suspender el procedimiento en España hasta que se dicte sentencia en el extranjero, y, si se ha producido dicha suspensión, para levantarla en cualquier momento. Vemos, pues, que a diferencia de las situaciones de litispendencia entre Estados de la UE contempladas en el art. 29 del Reglamento 1215/2012, la LCJIMC (igual que el art. 33, apdos. 1 y 2, del Reglamento de la UE para los casos de litispendencia "extracomunitaria») se limita a establecer una regla flexible, lo cual es lógico teniendo en cuenta que principalmente se aplicará en casos que quedarán fuera del marco integrado de la UE, y que las situaciones que puedan plantearse con los distintos Estados extranjeros pueden ser muy diversas. No hay que dar por supuesto que todos ellos estarán en condiciones de otorgar la debida tutela judicial de manera equivalente.

Por último, no está de más destacar que la nueva ley exige que, tanto la suspensión como su levantamiento, se promuevan a instancia de parte y previo informe del Ministerio Fiscal. Aparentemente, la primera de estas condiciones podría parecer razonable, porque en principio cabe suponer que la parte (normalmente el demandado en el segundo procedimiento en España) es quien tendría más interés en poner de relieve la pendencia de un proceso anterior en el extranjero, y también quien normalmente dispondría de mayores elementos de información al respecto. Ahora bien, tampoco cabe olvidar que esta solución plantea el inconveniente de que obliga al demandado en el segundo procedimiento, suscitado ante los jueces españoles, a comparecer ante ellos, con los consiguientes desembolsos que ello le pueda suponer, para posteriormente poder solicitar que se suspenda el curso de las actuaciones. Por esta razón, y aun cuando es cierto que a falta de iniciativa de la parte es posible que el juez español tenga dificultades para tener un conocimiento detallado de las circunstancias concretas de la litispendencia, ello no debiera impedir de manera total y absoluta la posibilidad de que el juez pueda verificar la situación de litispendencia de oficio, y eventualmente acordar la suspensión. Cabe recordar que el art. 33.4 del Reglamento 1215/2012 prevé, como regla, que el juez de un Estado miembro aplique dicho artículo a petición de la parte interesada, pero también permite que lo aplique de oficio, cuando el Derecho nacional así lo prevea. Lamentablemente, en el caso español el art. 39 de la LCJIMC, en sus apartados 1 y 2, no lo prevé.

En cuanto a la necesidad de informe previo del Ministerio Fiscal, cabe la duda de si esta exigencia, con carácter generalizado o para todos los casos, es realmente conveniente. Es decir, probablemente hubiera sido mejor limitar

10 Suderow, J., loc. cit. p. 196. 
la necesidad de informe del Ministerio Público a aquellos supuestos en que, por la naturaleza del litigio, concurriera un claro interés público o estuvieran en juego los derechos de personas merecedoras de una especial protección, como los menores. Fuera de estos casos, puede dudarse de la necesidad de dicha intervención, y en cambio debiera tenerse en cuenta el riesgo de posible retraso del procedimiento ocasionado por la necesidad de recabar el informe en cuestión.

Cuando el juez extranjero llegue a dictar sentencia, entonces nos encontraríamos, ya no ante una situación de mera litispendencia, sino de cosa juzgada en el extranjero. En tal caso, el art. 39.3 de la LCJIMC prevé que el juez español ponga fin al procedimiento y archive las actuaciones, esta vez con carácter obligatorio, siempre que el proceso en el extranjero haya concluido con una resolución susceptible de ser reconocida en España. La solución es idéntica a la que prevé el art. 33.3 del Reglamento 1215/2012, y es plenamente coherente con el nuevo sistema de reconocimiento de resoluciones establecido en el Título V de la LCJIMC, que se fundamenta en un reconocimiento automático o de pleno derecho de la sentencia extranjera, por lo que ya no será necesario solicitar el exequátur para obtener el reconocimiento ${ }^{11}$, a diferencia de lo que acontecía bajo el régimen de la LEC de 1881.

\section{REGULACIÓN DE LA CONEXIDAD INTERNACIONAL}

El caso de las demandas conexas se halla regulado en el art. 40 de la LCJIMC: se trata de aquella situación en la que hay demandas paralelas, aunque no idénticas, en España y en otro Estado, siendo la demanda en el otro Estado la primera en el tiempo. Aquí también se prevé que, a instancia de parte y previo informe del Ministerio Fiscal, el juez español pueda suspender el curso del procedimiento en España, y también que pueda levantar la suspensión en cualquier momento, si considera que ello es en el interés de una buena administración de justicia. Como en el caso de la litispendencia, para que pueda acordarse la suspensión se requerirá que pueda preverse que la futura sentencia extranjera cumplirá las condiciones para ser reconocida. A diferencia de los casos de litispendencia, en los de conexidad se requiere que sea oportuno oír y resolver las demandas conexas conjuntamente, a fin de evitar el riesgo de decisiones inconciliables. La lógica de esta condición implica que, si desaparece el riesgo de decisiones inconciliables, pueda levantarse la suspensión [art. 40.3.a)]. En definitiva, se trata de una regulación muy parecida a la del art. 34, apartados 1 y 2, del Reglamento 1215/2012.

La diferencia con el art. 34 del precitado Reglamento se encuentra en que, mientras que este, en su apartado 3, prevé de manera expresa qué hacer cuando el juez de un Estado tercero llegue a dictar una resolución (en tal caso, el juez del Estado miembro de la UE «podrá poner fin al proceso»), el art. 40 de

11 La disposición básica del nuevo sistema es el art. 44 LCJIMC. 
la LCJIMC, en cambio, guarda silencio. Ahora bien, la lógica nos diría que, si el procedimiento en España se ha suspendido en espera de que se dicte sentencia en el extranjero, dicha sentencia debiera ser tenida en cuenta. En esencia, habría dos posibilidades, teniendo en cuenta que en este contexto no se trataría de procesos paralelos idénticos, sino simplemente de demandas vinculadas o relacionadas. La primera, probablemente la más frecuente, sería que lo decidido en la resolución extranjera tuviera carácter de antecedente lógico con respecto al problema que se planteara en el procedimiento español, es decir, que nos halláramos ante una situación de prejudicialidad. En este supuesto, es obvio que el procedimiento español debiera continuar tras dictarse la resolución en el extranjero, pero tomando en consideración lo decidido en el extranjero a la hora de resolver el problema - distinto, aunque relacionado- planteado en el procedimiento español ${ }^{12}$.

La segunda posibilidad sería que, una vez producida la suspensión, una de las partes en el procedimiento en España hubiera planteado su demanda en el extranjero, habiéndose producido entonces una acumulación de acciones, y que el juez extranjero hubiera decidido sobre ambas. En este segundo supuesto, lo oportuno sería que el juez español archivara las actuaciones, siempre que la resolución extranjera reuniera las condiciones para ser reconocida en España. Esta solución sería plenamente coherente con la regla general de reconocimiento automático de la resolución extranjera (art. 44 LCJIMC) ${ }^{13}$, puesto que, al haberse acumulado la acción inicialmente ejercida en España al proceso extranjero, el juez extranjero estaría llamado a resolver un procedimiento idéntico. En estas circunstancias, si el juez extranjero llegara a dictar una resolución susceptible de reconocimiento que afectara a una acción que fuera la misma que aquella cuyo curso se hubiera suspendido en España, se impondría el archivo de la causa española. De hecho, estaríamos en la misma situación que prevé el art. 39.3 para los casos de litispendencia, con la única diferencia de que, estrictamente hablando, la acción causante de la cosa juzgada no se habría planteado antes en el extranjero, sino en España. Entonces, lo que justificaría que se diera preferencia al resultado del procedimiento extranjero sería que la demanda inicialmente planteada en España habría quedado paralizada o en suspenso por la existencia de una demanda conexa anterior en el extranjero, y que la parte interesada hubiera vuelto a plantear su pretensión en el extranjero, acumulándola a la demanda conexa.

\section{DETERMINACIÓN DEL MOMENTO DE INICIO DE LOS RESPECTIVOS PROCEDIMIENTOS}

Una cuestión clave en la regulación de la problemática de los procedimientos paralelos es la de determinar el momento a partir del cual se consi-

12 En este sentido, Garcimartín Alférez, F. J., Derecho internacional privado, Madrid, Civitas, 3. ${ }^{\mathrm{a}}$ ed., 2016, p. 212.

13 En este sentido, de Miguel Asensio, P. A., loc. cit., apartado III. 
deran pendientes, para así poder aplicar la regla del prior tempore. En principio, cabe suponer que la respuesta a la pregunta de cuándo se haya iniciado el procedimiento en cada uno de los foros implicados debiera responderse acudiendo a la regulación de cada uno de ellos, por tratarse de una cuestión inequívocamente procesal, a la que se aplicaría la regla lex fori regit processum. Sin embargo, el legislador español parece haber querido establecer una excepción a este principio en el art. 37 de la LCJIMC. Dice así: "A los efectos de este Título, un proceso se considerará pendiente desde el momento de interposición de la demanda, si después es admitida». Semejante redacción, de carácter amplio, induce a pensar que el legislador nos está diciendo, no únicamente cuándo un procedimiento debe considerarse pendiente en España, sino cuándo debe considerarse pendiente en general, en cualquier foro (obsérvese que la definición de pendencia se proporciona «a los efectos de este Título», sin ulteriores matizaciones o precisiones). Bien podría decirse que el legislador parece querer «exportar» la concepción española en cuanto al momento inicial de la litis $^{14}$, con la consecuencia de que podrían darse casos en que, a efectos de la ley española, un proceso se considerara pendiente en un Estado extranjero a partir del momento de presentación de la demanda en el mismo, mientras que en dicho Estado el cómputo inicial de la pendencia se situara en un momento distinto, por ejemplo cuando la demanda se traslada al demandado.

Desde una perspectiva técnica, podría objetarse que esta solución sería poco respetuosa con el punto de vista del foro extranjero implicado, y que podría dar lugar a soluciones dispares en los dos Estados en cuanto al momento de inicio del procedimiento. Ahora bien, también puede entenderse que el legislador español haya querido buscar un criterio uniforme y homogéneo, que aparentemente sería de más fácil aplicación para los jueces españoles, y que se haya resistido a dejar esta cuestión en manos de una ley extranjera, lo que hubiera obligado a los jueces españoles a tener que consultar en cada caso un Derecho procesal foráneo para dilucidar el momento de inicio de la pendencia en el extranjero.

Aun cuando puedan entenderse las razones de homogeneidad de criterio que parecen haber guiado esta solución, entiendo que hubiera sido preferible establecer una fórmula más amplia, teniendo en cuenta el contexto internacional en el que esta norma está llamada a aplicarse, y la gran variedad de regulaciones procesales nacionales: el momento a tener en cuenta debiera ser el de la primera actuación del demandante encaminada a poner en marcha el procedimiento, sea esta la presentación de la demanda, el traslado de la misma al demandado o, en los procedimientos judiciales en que una conciliación o mediación previa sea preceptiva, la petición de inicio de tal procedimiento previo a la fase judicial; o incluso la interposición de una denuncia o acción penal en la que el interesado ejerza, por sí o por medio del Ministerio Público,

14 Así se desprendería de la semejanza entre la fórmula retenida en el art. 37 de la LCJIMC y la que, con carácter general, aparece en el art. 410 de la LEC. 
una acción civil. En mi opinión, este criterio hubiera permitido preservar la homogeneidad buscada por el legislador y, al mismo tiempo, tener en cuenta las disparidades que pueden llegar a plantearse a causa de las diferencias de regulación de los distintos tipos de procedimientos en los diversos Estados. Es más, creo que es posible y deseable que el juez español llegue, por vía interpretativa y en atención a la finalidad de evitar futuras resoluciones inconciliables, a un resultado como el que aquí se defiende, mediante una interpretación amplia y flexible del concepto de «presentación de la demanda». Resulta de gran interés en este sentido la reciente STJUE de 22 de octubre de $2015^{15}$, en la que interpreta que, cuando una persona presenta una denuncia con personación como actor civil ante un juez de instrucción penal, el momento de presentación de dicha denuncia equivaldría al de presentación de la demanda o documento equivalente, a los efectos del art. 30 del Reglamento 44/2001 (art. 32 del Reglamento 1215/2012).

\section{TRAMITACIÓN PROCESAL DE LAS EXCEPCIONES DE LITISPENDENCIA Y CONEXIDAD INTERNACIONALES}

Según dice el art. 38 de la LCJIMC, las excepciones de litispendencia y de conexidad internacionales se tramitarán como la excepción de litispendencia interna y, en parecidos términos, el art. 22 nonies de la LOPJ (introducido mediante la LO 7/2015, de 21 de julio) ${ }^{16}$ proclama que tales excepciones se alegarán y tramitarán con arreglo a las normas generales que regulen las leyes procesales. Como ya tuve ocasión de señalar en otro lugar ${ }^{17}$, la litispendencia internacional no es propiamente un problema de competencia judicial, aunque suela estudiarse en el marco de los problemas de competencia internacional, sino que posee una sustantividad propia que justifica un tratamiento distinto. La regulación procesal interna trata como cuestiones distintas los problemas de litispendencia y cosa juzgada, por un lado, y los de competencia, por otro. De hecho, la cuestión de la competencia tendría un carácter previo a la de litispendencia, puesto que un juez solo podrá llegar a plantearse esta segunda cuestión si ya ha resuelto que es competente. Por el contrario, si llegara a la conclusión de que no es competente, debiera abstenerse de conocer, y entonces no tendría ninguna utilidad examinar si concurren otros motivos que pudieran repercutir en la continuación del procedimiento ${ }^{18}$.

Por consiguiente, la consideración de las excepciones de litispendencia y conexidad como una cuestión procesal diferenciada tiene una importante incidencia en la articulación procesal de tales excepciones: debieran tramitarse, no por la vía de la declinatoria, porque realmente no se estaría impugnan-

\footnotetext{
15 As. C-523/14.

16 BOE de 22 de julio.

17 «Litispendencia y cosa juzgada en el extranjero ante la nueva LEC», AEDIPr., t. I, 2001, pp. 325-326.

18 Málaga Diéguez, F., op. cit., pp. 310-312.
} 
do la competencia judicial internacional de los Tribunales españoles, sino por la de la contestación a la demanda, ya que en el sistema previsto en la LEC la cosa juzgada y la litispendencia son excepciones de carácter procesal que el demandado tiene que alegar en la contestación (arts. 404, 410-413, 416.1.2. , 421 y 438 LEC). Es más, si, como establecen los arts. 39, apartados 1 y 2, y 40 LCJIMC para el caso específico de la litispendencia y conexidad internacionales, lo que puede pedirse al juez es la suspensión del procedimiento en España, entonces está claro que la declinatoria no es el cauce procesal apropiado. En efecto, la estimación de la declinatoria tendría como consecuencia que el juez se inhibiera del caso y archivara las actuaciones (art. 65.2 LEC), pero no una posible suspensión ${ }^{19}$.

\section{RÉGIMEN APLICABLE A LOS PROCEDIMIENTOS INICIADOS CON ANTERIORIDAD A LA NUEVA LEY}

Concluyendo, cabe decir que, en virtud de lo que establece la disposición transitoria única de la LCJIMC, en su apartado segundo, las nuevas reglas sobre litispendencia y conexidad internacionales se aplicarán «a las demandas que se presenten ante los órganos jurisdiccionales españoles con posterioridad a la entrada en vigor de la ley», y dicha entrada en vigor se produjo a los veinte días de su publicación en el BOE (DF $6 .^{\mathrm{a}}{ }^{20}$. Por tanto, a partir de dicha fecha, existe una regulación expresa de la litispendencia y conexidad internacionales en el Derecho español de fuente autónoma, regulación de la que antes se carecía. Ahora bien, como ya tuve ocasión de defender hace unos años, que no existiera una regulación expresa no quiere decir que resultara imposible tener en cuenta, a los efectos de un procedimiento abierto en España, la pendencia de un proceso en el extranjero ${ }^{21}$. En los últimos años, la jurisprudencia también se habría mostrado favorable, al menos implícitamente, a la admisión de la litispendencia internacional, como demostraría la STS de 23 de febrero de $2007^{22}$. A falta de normas expresas, el intérprete podría recurrir a disposiciones generales de nuestro Derecho procesal, adaptándolas a las particularidades de la litispendencia internacional. Las disposiciones idóneas serían, en mi opinión, el art. 43 de la LEC, que contempla las situaciones de prejudicialidad civil y, al menos para algunos casos, el art. 247 del mismo cuerpo legal, que ordena a los Tribunales rechazar cualquier petición formulada con manifiesto abuso de derecho ${ }^{23}$. Pues bien, los supuestos de

19 Otra cuestión procesal del máximo interés es la de las normas sobre condena en costas, cuya aplicación en los supuestos de litispendencia y conexidad internacionales debe responder a las especificidades de estas excepciones, y a la diversidad de supuestos que pueden llegar a plantearse; sobre esta cuestión, véase el interesante trabajo de CARRILlo Pozo, L. F., «Litispendencia internacional y costas del proceso", Bitácora Millennium DIPr, 2015, núm. 2, pp. 113-127 (http://www.millenniumdipr.com/).

${ }^{20}$ Como ya se ha señalado, la ley se publicó en el $B O E$ de 31 de julio de 2015, y por tanto entró en vigor el 20 de agosto.

21 «Litispendencia...», cit., pp. 315-327.

22 Tuve ocasión de comentarla en AEDIPr, t. VII, 2007, pp. 904-907.

23 «Litispendencia...», cit., pp. 325-337. 
litispendencia o conexidad internacionales que se susciten a raíz de acciones presentadas en España antes de la entrada en vigor de la Ley 29/2015 podrían resolverse con el auxilio de estas disposiciones.

Palabras clave: litispendencia internacional, conexidad internacional, Ley de Cooperación Jurídica Internacional en Materia Civil (Ley 29/2015).

Keywords: lis pendens, related actions, Spanish Statute on international legal cooperation in civil matters (Law 29/2015). 